\title{
Stigma by Association Among Family Members of People with a Mental IIIness: A Qualitative Analysis
}

Citation for published version (APA):

van der Sanden, R. L. M., Bos, A. E. R., Stutterheim, S. E., Pryor, J. B., \& Kok, G. (2015). Stigma by Association Among Family Members of People with a Mental IIlness: A Qualitative Analysis. Journal of Community \& Applied Social Psychology, 25(5), 400-417. https://doi.org/10.1002/casp.2221

Document status and date:

Published: 01/01/2015

DOI:

10.1002/casp.2221

Document Version:

Publisher's PDF, also known as Version of record

Document license:

Taverne

Please check the document version of this publication:

- A submitted manuscript is the version of the article upon submission and before peer-review. There can be important differences between the submitted version and the official published version of record.

People interested in the research are advised to contact the author for the final version of the publication, or visit the DOI to the publisher's website.

- The final author version and the galley proof are versions of the publication after peer review.

- The final published version features the final layout of the paper including the volume, issue and page numbers.

Link to publication

\footnotetext{
General rights rights.

- You may freely distribute the URL identifying the publication in the public portal. please follow below link for the End User Agreement:

www.umlib.nl/taverne-license

Take down policy

If you believe that this document breaches copyright please contact us at:

repository@maastrichtuniversity.nl

providing details and we will investigate your claim.
}

Copyright and moral rights for the publications made accessible in the public portal are retained by the authors and/or other copyright owners and it is a condition of accessing publications that users recognise and abide by the legal requirements associated with these

- Users may download and print one copy of any publication from the public portal for the purpose of private study or research.

- You may not further distribute the material or use it for any profit-making activity or commercial gain

If the publication is distributed under the terms of Article $25 \mathrm{fa}$ of the Dutch Copyright Act, indicated by the "Taverne" license above, 
Journal of Community \& Applied Social Psychology

J. Community Appl. Soc. Psychol., 25: 400-417 (2015)

Published online 19 January 2015 in Wiley Online Library

(wileyonlinelibrary.com) DOI: 10.1002/casp.2221

\title{
Stigma by Association Among Family Members of People with a Mental Illness: A Qualitative Analysis
}

\author{
REMKO L. M. VAN DER SANDEN ${ }^{1 *}$, ARJAN E. R. BOS ${ }^{2}$, \\ SARAH E. STUTTERHEIM ${ }^{2}$, JOHN B. PRYOR ${ }^{3}$ and GERJO KOK ${ }^{1}$ \\ ${ }^{1}$ Maastricht University, Maastricht, The Netherlands \\ ${ }^{2}$ Open University of the Netherlands, Heerlen, The Netherlands \\ ${ }^{3}$ Illinois State University, Normal, IL, USA
}

\begin{abstract}
People with mental illness are not the sole recipients of stigmatisation; their immediate family members may be subjected to stigma by association. Through semi-structured interviews, we investigated experiences of stigma by association among 23 immediate family members of people with mental illness. Participants reported experiencing stigma by association from community members, mental health professionals, and civil servants. Familial relationship, co-residence, and the gender of participants appeared to play a role in their stigma experiences; parents and spouses reported different manifestations of stigma by association than siblings and children, participants who lived together with their family member with mental illness reported increased experiences of stigma by association, and in contrast to male participants, female participants reported others thinking they are overprotective and as such perpetuated, maintained, or sustained their family members' mental illness. The relevance of these factors points to the need for tailored education and emotional support provision to family members of people with mental illness. Moreover, inservice training for mental health professionals should include the development of relevant social skills that enable the recognition of familial relationships and roles, and family members' fears, concerns, and problems. Copyright @ 2015 John Wiley \& Sons, Ltd.
\end{abstract}

Key words: stigma by association; mental illness; familial relationship; co-residence; gender

People with mental illness (PWMI) are more likely to be unemployed, have less income, and have less social support (Link \& Cullen, 1990). Labelling theory attributes these deficits partly to the stigma of mental illness (Link, Cullen, Struening, Shrout and Dohrenwend, 1989). The term stigma originally refers to a discrediting characteristic that renders someone flawed, degraded, or inferior in the eyes of others (Crocker, Major \& Steele, 1998). Nowadays, stigma is seen not as a physical mark or characteristic but rather

*Correspondence to: Remko van der Sanden, Department of Work and Social Psychology, Faculty of Psychology and Neuroscience, Maastricht University, PO Box 616, 6200 MD Maastricht, The Netherlands.

E-mail: remco.vandersanden@maastrichtuniversity.nl 
as an attribute that results in widespread social disapproval (Bos, Pryor, Reeder, \& Stutterheim, 2013). Dovidio, Major, and Crocker (2000) emphasised that definitions of stigma mostly comprise two components: difference and devaluation. To trigger stigmatising behaviour, the stigma should be noticeable and devalue one's social status. This may result in avoidance, blaming, exclusion, and other negative social interactions (Bos, Kanner, Muris, Janssen, \& Mayer, 2009).

Stigma may also 'spill over' from people with a stigmatised condition to people associated with them, for example, family and friends. This is known as courtesy stigma, family stigma, or stigma by association (SBA; Bos et al., 2013; Corrigan, Watson, \& Miller, 2006; Goffman, 1963; Lefley, 1989; Pryor, Reeder, \& Monroe, 2012). SBA can lead to social exclusion, avoidance of social interactions, negative treatment, and the expenditure of energy and resources to conceal one's familial relationship with a stigmatised person (Larson \& Corrigan, 2008). Studies have demonstrated that SBA can also affect the well-being of family members of people with a stigmatised condition like mental illness, resulting in psychological and physical health complaints (Angermeyer, Schulze, \& Dietrich, 2003; Östman \& Kjellin, 2002; Van der Sanden, Bos, Stutterheim, Pryor, \& Kok, 2013).

Research has shown that when the onset or continuation of a stigmatised condition like mental illness is perceived to be something over which one has control, others are more likely to view one as personally responsible for the condition, which may result in negative emotional reactions and subsequent stigmatisation (Bos et al., 2008; Bos et al., 2009; Phelan, Bromet, \& Link, 1998; Van der Sanden, 2006; Weiner, Perry, \& Magnusson, 1988). Corrigan and Miller (2004) have shown that this applies not only to PWMI but to their family members as well.

However, the term 'family' implies a variety of familial relationships (e.g. parents, spouses, children, and siblings) and responsibilities that differ across family members (Corrigan \& Miller, 2004; Eldering, 2006). As such, it is likely that different family members experience different expressions of SBA. Corrigan and Miller (2004) found that spouses and parents are frequently blamed for the onset and continuation of their family members' mental illness, while siblings and spouses are frequently held responsible for a family member's lack of treatment adherence, and children of PWMI often fear becoming 'contaminated' by their parents' mental illness. Mehta and Farina (1988) and Farina (2000), in their investigations of why community members extend mental illness stigma to other, previously non-stigmatised family members, found that family members are stigmatised because people who appear together in public seem alike, and someone who voluntarily chooses to associate with a stigmatised person must be deviant as well. Furthermore, research has shown that also gender is regularly, however not indisputably, a factor in stigma experiences of PWMI (Farina, 1981; Östman \& Kjellin, 2002; Wirth \& Bodenhausen, 2009). In fact, Wirth and Bodenhausen (2009) demonstrated that when stigmatised conditions, symptoms, and behaviour are considered gender typical, blaming is more likely (Wirth \& Bodenhausen, 2009).

In this qualitative study, we comprehensively explored the experiences of SBA among immediate family members of PWMI while paying particular attention to the characteristics of familial relationship, co-residence, and gender in order to better understand how experiences of SBA affect various immediate family members of PWMI and in order to enable the identification of adequate tailored support and education for family members of PWMI. 


\section{METHOD}

\section{Participants and procedure}

After approval by the Ethics Committee at Maastricht University's Faculty of Psychology and Neurosciences, 23 immediate family members (i.e. spouses, children, siblings, and parents) of PWMI were recruited for face-to-face, semi-structured interviews. ${ }^{1}$ Nineteen participants were recruited through announcements distributed by Dutch mental health self-help support groups and professionally operated support groups. Four participants were recruited directly by the first author. The self-help support groups are characterised by a desire to overcome difficulties associated with family members' mental illness and increase well-being and quality of life through bottom-up support and information seeking, empowerment, and the creation of communities of family members of PWMI. The professionally operated support groups are groups facilitated by mental health professionals with guided conversations that seek to allow family members of PWMI to share their experiences, acquire relevant information, establish social networks, and influence public opinion and policy. Demographic and background characteristics for all participants are displayed in Table 1. An overview on familial relationship, co-residence, and gender per participant is provided in Appendix A.

Once recruited, participants were given information about the study's purpose and procedure, informed consent was obtained, and interviews were held by the first author between March 2012 and April 2013 at a location deemed appropriate by the participant. The interviews lasted approximately 90 minutes and were guided by a structured protocol of open-ended questions with follow-up probes. The interview protocol was derived from existing literature on stigmatisation and SBA (e.g. Angermeyer et al., 2003; Corrigan et al., 2006), validated scales for assessing experiences of SBA and psychological distress (e.g. Mental Health Inventory, Veit \& Ware, 1983; Stigma-by-association scale, Pryor et al., 2012), and previously used protocols (e.g. interview protocol, Stutterheim et al., 2011). A pilot protocol with themes, questions, and follow-up probes was participatively pretested among family members of PWMI, mental health professionals, and PWMI, and then adjusted based upon the feedback provided. The revised protocol was then tested again in three interviews with family members of PWMI, and adjustments were once again made based on the feedback. The final protocol explored the following:

(1) participants' SBA experiences as well as their perceptions regarding how their community views mental illness and family members of PWMI;

(2) participants' perceptions regarding the extent to which they felt that SBA experiences have affected their lives and well-being; and

(3) participants' perceptions regarding the extent to which familial relationship, coresidence, and gender are relevant to SBA experiences.

All interviews were recorded with a digital voice recorder and transcribed verbatim. Data were processed with QSR NVivo 9.0, and thematic content analysis was conducted (Burnard, Gill, Stewart, Treasure, \& Chadwick, 2008; Thomas, 2006). In this

\footnotetext{
${ }^{1}$ Another manuscript that drew upon another part of the data set that explored coping with stigma by association and family burden has been published elsewhere (Van der Sanden, Stutterheim, Pryor, Kok, \& Bos, 2014). 
Table 1. Demographic and background characteristics of sample

\begin{tabular}{lc}
\hline Variable & Percentage (\%) \\
\hline Gender & \\
Male & 47.8 \\
Female & 52.2 \\
Age & \\
Years [mean $(S D)]$ & $44.3(12.6)$ \\
Range (min-max) & $25-64$ \\
Marital status & \\
Single & 13.1 \\
Married & 52.1 \\
Divorced & 21.7 \\
Widowed & 13.1 \\
Family relationship & \\
Spouse & 20.7 \\
Child & 20.7 \\
Parent & 27.5 \\
Sibling & 31.1 \\
Family members' mental illness & \\
Depressive, bipolar, or other mood disorders & 52.2 \\
Personality disorder & 17.4 \\
ADHD/ADD & 17.4 \\
Dissociative disorder & 13.0 \\
Autism & 13.0 \\
Schizophrenia or psychotic disorder & 8.7 \\
Addiction & 4.3 \\
\hline
\end{tabular}

Note: $\mathrm{ADHD}=$ attention deficit disorder with hyperactivity; $\mathrm{ADD}=$ attention deficit disorder.

Because some family members were diagnosed for more than one mental illness, the percentage of illnesses exceeds $100 \%$.

process, the first author first listened to the recordings and then thoroughly examined the transcripts to identify relevant themes and items (open coding; see Appendix B). Subsequently, themes and items were categorised by the first author (RvdS), with the support of the second (SS) and fifth authors (AB), by identifying similarities and differences in the data. Themes and items were then further explored, and a hierarchical data structure based upon these themes and items was developed (Bazeley, 2007; Polit \& Beck, 2010). The creation of this data structure with nodes and attributes was subject to discussion and consultation among all authors and thus evolved into a concerted node structure that accounted for all data. Changes to the hierarchical data structure and the reasons for those changes (i.e. a decision trail) were maintained (Burnard, 2004; Polit \& Beck, 2010).

\section{RESULTS}

Participants reported various experiences of SBA. They also spoke of the kind and impact of their familial relationship with a PWMI, provided opinions about the role of coresidence, and discussed gender aspects in the context of their experiences with SBA (see Appendix C for the reported items per participant). 


\section{Experiences of stigma by association}

Participants claimed that not only are PWMI affected by stigma, they, as family members, are affected as well. They indicated that their community members often have oversimplified images of mental illnesses, of PWMI, and of their family members. They also reported community members having negative attitudes and displaying discriminatory behaviour towards PWMI and their family members:

I was getting ready to go for a walk and I was outside. I put him [her youngest son] in the stroller and I was locking the door and stuff. So, this little boy [neighbour] comes over to my son [without mental illness] and wants to talk to him and what does my neighbour do? She pulls that kid away from him [participant's son] and hollers at me, 'That's contagious!' I think, 'Contagious? What are you talking about?' 'Yeah, contagious what you guys have and he [participant's — absent — son with mental illness] even takes that bus to that special school, so it's contagious.' (Karen, mother, age 58)

Participants mentioned experiencing SBA regularly and found themselves 'labelled' as incompetent, responsible for the stigmatised condition, unpredictable, and different:

We were also considered pitiful, weird, and unpredictable, and they didn't take us seriously when we asked them to help. It was our own fault and things would just work themselves out. (Celia, sister, age 46)

Participants further reported experiencing social distance, having fewer social contacts, and smaller social networks because they had a family member with mental illness. They spoke of avoidance, rejection, and abandonment:

Speaking of stigmatisation, those two girls, they'd been really good friends for at least five years and then, out of the blue, contact was discontinued because the father was psychotic. The daughter was looked down upon. She was no longer welcome there and contact had to be broken because her father had had a psychotic break. (Karen, mother, age 58)

In fact, almost all participants described changed or broken relationships with family, being alienated from friends, or having smaller social networks as a result of SBA and manifest as social distance, blame, or negative remarks and dismissal:

Your world becomes smaller and smaller. You have fewer social contacts, you lose friends, and you become socially isolated. It just seems to happen over time. (Roy, husband, age 45)

In addition to experiencing altered or broken relationships and being alienated from friends and extended family members, participants also spoke of being inhibited in social situations from speaking openly about their family member:

You know, when you're with company, they say, ahead of time, 'Let's keep things light. Let's not talk about that stuff, your sick daughter or the difficulties or how hard it is for you'. People want you to be the old you. Everything's fine. Everything should be fine. 
Don't talk about it. Don't be weird. Some even avoid you for a good long time. (Suzanne, mother, age 59)

Some participants indicated that they reduced contact with family members, friends, and acquaintances, and avoid some forms of social engagement in order to avoid having to talk or not talk about their family member with mental illness. Participants also mentioned avoiding social events because they did not want to be confronted with stigmatising reactions by others.

\section{Stigma by association in contact with mental health professionals and civil servants}

Although not explicitly investigated by our interview protocol, a theme that frequently arose in the data was SBA in contacts with mental health professionals and civil servants. In fact, more than half of the participants in this study explicitly mentioned having experienced SBA in these contacts. Parents and spouses, in particular, experienced being held responsible and blamed by civil servants and mental health professionals for their family members' mental illness:

And then the first one came, ready with his bias. He was from children's services. That man, he came inside and we were shocked. He showed up and was like, 'Parents, you've done it all wrong.' He had an enormous preconceived idea. He stigmatised us. We needed more than half an hour to convince him that we had done everything we could and that we had two other children and there were no problems with them. You constantly need to defend yourself. (Renske, mother, age 59)

Additionally, participants reported perceiving a lack of interest on the part of civil servants and mental health professionals. They often felt that their perspectives on care, their familial relationship with their family member, and the problems and concerns present were not taken seriously:

Being taken seriously? In healthcare? I've become so frustrated [hits table]. As the mother of a sick kid, mothers don't count, mothers are no longer part of it. They [children with mental illness] are no longer your problem [points to forehead to indicate 'crazy']. Of course they are, but then, all of the sudden, it's your fault. You're part of the problem. (Emma, mother, age 59)

In fact, many participants reported feeling ignored by professionals and complained that they had been excluded from the treatment process - that professionals had rejected their cooperation and involvement despite having been, often for years, the sole provider [s] of support to their family member[s] with mental illness. They further reported feeling as though they were seen as incompetent, a nuisance, and an additional burden. Several parents and spouses reported feeling particularly frustrated and angry because they had, for a long time, been fully responsible for their family member, had backed and supported their child or spouse for years, and then, when professional treatment or hospitalisation occurred, they felt they were 'left out of the team' and did not get adequate information. 
And then, when he was admitted - he went there himself - and I wanted to know how he was doing. I was put out in the hallway where everyone can walk by and there I was told that they wouldn't give me any information because he didn't want that. I wasn't even invited into the office. Nothing. People were there walking around, visiting and doing whatever and they could hear everything. That's mental health services for you. But you're so tired, so incredibly tired, dog-tired. You're no longer resilient or you're so resilient that you get mad. I, at that point in time, you might say, 'flipped out'. Nope, nothing. No, I didn't feel taken seriously at all. In fact, I felt like they looked down on me. I felt like they had pushed me back into a corner. (Anja, wife, age 61)

\section{Familial relationship, co-residence, and gender}

In their interviews, participants discussed the extent to which they perceived their familial relationship, co-residence, and gender to be relevant to their experiences of SBA.

\section{Familial relationship}

Participants that were differently connected to their family member with mental illness did appear to report different kinds of SBA experiences. Parents and spouses regularly reported having been held responsible for the onset and perpetuation of their family member's mental illness, as exemplified by comments about them being a poor or less competent parent or spouse:

I felt like she held me responsible. There were remarks about me not being a good mother. I totally panicked and I drove home and I thought that I had indeed done it all wrong. (Emma, mother, age 59)

They told me, 'Do something about it!' But what could I do? Go and hide all the money and food in the house? And they certainly blamed me for her condition. What could I do? Force her to adhere to treatment? (Dick, husband, age 54)

In contrast, children and siblings spoke more generally about experiencing stigmatisation, mostly from other parents and children in their communities and mainly in their puberty and adolescence. Most frequently reported among siblings and children was being seen as different or even deviant by others. This subsequently evoked shame and often led to efforts to conceal the relationship with a PWMI in order to avoid negative reactions and the potential loss of friendships and even (potential) romantic relationships:

Then I thought, 'Fuck off! Get out of my life!' In those moments, I felt ashamed and I always considered it [when making plans with friends] and avoided her and those situations and the contact. I never talked about her. (Joep, brother, age 43)

Children and siblings of PWMI reported that although experiences of SBA were particularly stressful during their puberty and adolescence, as they grew older and moved out of the family home, SBA experiences lessened and became more manageable. 
Another crucial time for children of PWMI occurred when they started a family of their own. One participant mentioned how family members and acquaintances advised her not to have children because of the mental illness in her family. Similarly, some children and siblings of PWMI reported being concerned that their children would inherit their family member's mental illness, would later on experience stigmatisation, and that history [mental illness stigma and SBA] would repeat itself in yet another generation:

But, you do it anyhow [have children]. I mean it's not only hard for you as a parent but also for that kid. I think it would be horrible [to have schizophrenia]. So yes, I've considered it when thinking about whether I want to have children. (Liza, sister, age 30)

\section{Co-residence}

One participant, who had previously lived together with his sister with mental illness, mentioned taking her mental illness, and even her physical presence, into account when with friends, especially when he invited friends over to his house. He felt her behaviour brought stigmatisation upon both her and him and that he too would be perceived as different or deviant. He also felt that he had had fewer opportunities to meet and connect with others because of his sister's mental illness, her behaviour, and their co-residence:

You become calculated in your interactions and you take her presence, or rather her absence, into account when you plan something - who, what, when, with what. You avoid her and her illness and you don't tell anyone but because we, soon after, no longer lived in the same house, it was liveable and I was less ashamed than I would have been had I still lived in the same home. (Joep, brother, age 43)

This kind of experience was quite common among siblings and children who lived together with their family member with mental illness. Often, participants conveyed how their perceived experiences of SBA and resulting distress increased when they, mostly in their early teens, became increasing aware of others' reactions to their family member with mental illness and the family as a whole. These participants reported that they, especially in their puberty and adolescence, actively avoided their family member in order to prevent or mitigate experiences of SBA. They also mentioned that their experiences of SBA decreased substantially when they left the household where they and their family member lived together:

I moved in with my boyfriend sooner because of it [sister's mental illness]. I left. I left the situation at home. She lived there, my parents lived there, and I didn't want to be seen as part of the problem anymore. I left and so I left a lot of it behind. When you move out, you're no longer right in the middle of it and you're no longer part of it and I didn't want to be part of it anymore. (Ria, sister, age 45)

\section{Gender}

The data suggest that women are more frequently held responsible for the mental illness of a family member than men are. In fact, many of the women in this study reported 
experiencing or observing accusations that they were or had been overprotective and thus had caused, contributed, or sustained their family members' mental illness:

My in-laws found me to be overprotective. I kept the problem going on they said. They told me to throw my son out of the house and to let him be. According to them, I was overprotective and I sustained his mental illness and his problems. (Natasja, mother, age 57)

Another participant recalled her mother being accused several times of being overprotective and as such causing and continuing her daughter's mental illness:

That happened a lot. It happened to my father and my mother too. They were told all sorts of things but it was mostly my mother and it was mostly about her being too protective. She needed to be firmer, that it was her fault because she wasn't firm enough with her [daughter with mental illness]. (Celia, sister, age 46)

Interestingly, these accusations appeared to be geared exclusively to female family members of PWMI, and particularly mothers, as none of the male participants in our study reported such accusations.

\section{DISCUSSION}

This study set out to document the experiences of SBA among immediate family members of PWMI while taking into account relevant influencing factors including familial relationship, co-residence, and gender.

\section{Stigma by association}

Participants reported a broad range of SBA experiences. The findings suggest that family members of PWMI experienced negative treatment and not being taken seriously, but, above all, they experienced and observed other immediate family members being blamed and being held responsible for their family members' mental illnesses and behaviour. They also reported that SBA disrupted social relationships and led to social distance. Family members indicated that these experiences were very stressful and diminished their wellbeing. This is in line with Angermeyer et al. (2003) and Van der Sanden et al. (2013) who found that SBA of families of PWMI leads to psychological distress, diminishes well-being, and negatively impacts their relationships with others.

Previous research has shown that members of the general public often manifest an immediate and sometimes even unconscious aversion to people with a stigmatised condition that can be followed by discriminating and devaluating behaviour (Stutterheim et al., 2011). Weiner et al. (1988) have shown that stigmas that were perceived as more controllable elicit less pity, arouse more anger, and lead to accusations of negligence. Most likely, the onset and continuation of mental illnesses of PWMI are perceived by the general public as, at least partly, controllable by the family members of PWMI (Weiner et al, 1988). For 
this reason, family members appear to be seen as personally responsible for their family member's mental illness and the stigmatised condition, leading to experiences of SBA.

Yet, in regard to the experiences of SBA upon family members of PWMI in our study, social distance appeared to not only derive from the actions of others; self-imposed withdrawal from existing social networks and social events occurred as well. Family members of PWMI appeared to make specific choices with regard to which social networks and social events they wanted to maintain. It is possible that these participants were sensitive to negative experiences, including SBA, and thus avoided social experiences and social events to reduce the risk of rejection and stress (Philips \& Benoit, 2013). Withdrawal from one's social network and social events might also have been necessary to prevent emotional exhaustion (Verhaeghe \& Bracke, 2012).

\section{Stigma by association in contacts with mental health professionals and civil servants}

More than half of the participants in this study reported experiencing SBA in their contacts with mental health professionals and civil servants. Participants also reported feeling little to no support in handling the burden of being related to a PWMI from mental health professionals or civil servants. These findings are in accordance with Östman and Kjellin (2002) who found family members of PWMI to have stigmatising experiences with staff members of mental health hospitals.

While mental health professionals and civil servants are likely well trained in the individual rights of and their legal obligations towards PWMI, they may not give sufficient consideration to family members' familial responsibilities, adjoining problems, and their justifiable concerns, and this is likely to be what is perceived as SBA by family members. Addressing this is important as perceived exclusion from the treatment processes may lead to diminished social support provision to PWMI by family members during periods of hospitalisation and thereafter. Also, a lack of adequate information provision due to privacy regulations or medical confidentiality can be perceived as very stigmatising by family members. This is consistent with Angermeyer et al. (2003), who found inadequate flows of information to be regarded as a form of structural discrimination. However, Angermeyer et al. (2003) also noted that family members' critique that they had been blamed by mental health professionals and civil servants may not necessarily imply that they were explicitly blamed but rather family members of PWMI may react sensitively to possible accusations or signs of rejection.

\section{Familial relationship}

In our study, experiences of SBA appeared to be impacted by the familial relationships participants had with their family members with mental illness. Parents and spouses seemed to have rather similar experiences of SBA (i.e. avoidance, being blamed, and negative treatment), and as a consequence, they felt ashamed, guilty, and sometimes helpless, whereas siblings and children mainly reported rejection and abandonment, and feared contamination. These findings are partly similar to those of Corrigan and Miller (2004) who found that parents tend to be blamed for the onset of their children's mental illnesses, spouses and siblings tend to be held responsible for not assuring their family members adhere to treatment plans, and children tend to be fearful about becoming contaminated by their parent's mental illness. The similarity between parents and spouses in their experiences of 
SBA may emerge from the general publics' view on parents' and spouses' societal roles as caregivers, and their perceived personal responsibility for the familial relationship and stigmatised condition (Bos et al., 2008; Corrigan \& Miller, 2004; Weiner et al., 1988). In this context, parents and spouses face blame because they are held responsible for the upbringing of their children or for influencing and correcting their spouses (Angermeyer et al., 2003). Children and siblings of PWMI in this study, however, were more infrequently deemed the role of caregiver and were thus less likely to be considered personally responsible for the mental health condition of their family member, moreover as they did not voluntarily choose the familial relationship. Furthermore, none of the siblings in this study reported the family member with mental illness to obstruct or not to adhere to treatment plans. Possibly, for these reasons did siblings in this study not report experiences of being held responsible for treatment nonadherence. Nevertheless, siblings and children appeared to be seen as potentially deviant people as a result of their association with a PWMI, especially by their peers during their puberty and adolescence, resulting in abandonment and social rejection. Clearly, the different kinds of familial relationships appear to have different experiences because they have different roles and responsibilities within the family (Eldering, 2006).

\section{Co-residence}

The results in this study further suggest that co-residing with a PWMI may impact SBA experiences. Family members, especially siblings, reported that living together with their family member with mental illness increased their experiences of SBA and impacted the frequency and context of their social contact with others. These findings are in line with Conde-Sala, Garre-Olmo, Turro-Garriga, Vilalta-Franch, and Lopez-Pousa (2010), who found in their study among caregiving family members that living with a PWMI had a notable influence on the social burden and psychological distress among these family members and, as such, worsened their mental health condition. Lanquetot (1988), in her report on being an immediate family member of PWMI found that co-residence reinforced feelings of shame, embarrassment, social exclusion, rejection by friends and acquaintances, concealment, and the need of getting away from home and to escape from the stigmatised situation. It is quite possible that living together with a family member with mental illness makes the familial connection more noticeable and salient, decreases the success of efforts to conceal or selectively disclose one's connection to a PWMI, and thus lays the groundwork for increased SBA (Dovidio et al., 2000; Kulik et al., 2008; Lanquetot, 1988). In that way, living with a family member with mental illness may exacerbate experiences of SBA as social exclusion, rejection, and abandonment, and increase one's psychological distress (Bos et al., 2009).

\section{Gender}

In contrast to male participants, female participants frequently reported others thinking they are overprotective, and through that overprotectiveness, they perpetuate, maintain, or sustain their family members' mental illness. These findings are analogue to findings by Wirth and Bodenhausen (2009), who found that gender-typical cases of mental illness, symptoms, or behaviour elicit negative affect, less sympathy, and less support. Possibly, women are seen as more caring than men and are thus seen as overprotective or patronising 
by others. This appears to be consistent with the social role theory proposed by Eagly, Wood, and Diekman (2000), a theory that contends that men and women behave differently in social situations and take on different roles as a result of different expectations placed upon them by society. As such, overprotectiveness may be perceived as a gender-typical behaviour by the general public. Gender differences, gender-typical symptoms, and stigmatisation have been previously studied by Wirth and Bodenhausen (2009), and although their study focused on the relationship between gender and public stigma, some of the processes they uncovered may analogue to the processes at play in the relationship between gender and SBA. Specifically, Wirth and Bodenhausen (2009) examined whether a PWMI's gender moderates the degree of stigma experienced and found that gender-typical behaviour is attributed to the personal traits of the actor, what may result in greater blame, and being held personally responsible for the stigmatised condition (Weiner, 1995; Wirth \& Bodenhausen, 2009). In the context of female family members of PWMI, it may be that overprotectiveness lends itself to blaming as it is perceived by others to represent typically female behaviour and may lead them to hold these women personally responsible for the onset or continuation of their family members' mental illness (Wirth \& Bodenhausen, 2009).

\section{Strengths and limitations}

Our study has both strengths and limitations. The primary strength is the inductive nature of our research and the extensive and 'thick' descriptions that capture the contextual experiences of SBA among family members of PWMI. A second strength is the involvement of PWMI, their family members, and mental health professionals, as well as the application of previously validated scales and protocols, in the development of this study's interview protocol. We set out to ensure the quality, reliability, and validity of this qualitative study by using this semi-structured interview protocol to guide the interviews. Furthermore, rigour was sought by maintaining a transparent decision trail throughout the study, by checking our findings with relevant stakeholders, and through theory triangulation (Polit \& Beck, 2010).

Our study also has some limitations. Given that our sample size was, although adequate for an exploratory study, small, caution should be applied in generalising the results from this study to other populations. At the same time, it is important to recognise that qualitative research does not necessarily seek to attain generalizability. It can, however, be transferable and thus invites readers to make connections between elements of this study and their own experiences (Lincoln \& Guba, 1985). Another limitation was that study participants were mainly recruited through support groups. Recruitment through support groups may have led to selection bias as those participants who seek support may be more unsatisfied with professional services or because those who volunteered may be the most dissatisfied among group members. On the other hand, the interviews and interview protocol principally focussed on experiences of SBA in a settings beyond mental health services, namely in participants' communities and society as a whole. Another potential limitation was the use of retrospective reports and subsequent recall bias. Recall bias was, however, combatted, at least to some extent, by asking follow-up questions to attain clearer and more detailed insight regarding participants' experiences of SBA. Lastly, in our study, coding was conducted primarily 
by the first author. Having multiple coders and determining interrater reliability may have enhanced the rigour of this study.

\section{Practical implications}

Our findings suggest several practical implications. First, they suggest that there is a need for the provision of tailored support to family members of PWMI that takes familial relationship, co-residence, and gender into account. Specific attention should be paid to the particular needs of immediate family members who frequently act as caregivers, and siblings and children of PWMI in their puberty or adolescence. Services and facilities that provide respite from caring for a PWMI are likely to be highly beneficial. Furthermore, the extent to which family members provide social support and help their family member should be acknowledged and reinforced by community members, and mental health professionals. It is also important that mental health professionals should be aware of the stigmatising effect and stress that can result from inadvertently excluding immediate family members from treatment processes and inadequate flows of information. We therefore recommend that in-service training for mental health professionals and civil servants include the provision of information, create opportunities for discussion, and build skills as they pertain to how professionals can best support family members and acknowledge their responsibilities and concerns.

\section{Conclusion}

In conclusion, this study has contributed to our understanding of various processes underlying SBA among immediate family members of PWMI. Participants reported that SBA experiences have negatively impacted their psychological well-being and social lives. Also, this study has shown that familial relationships, co-residence, and gender affect the SBA experiences of family members of PWMI. The relevance of these characteristics combined with the variety of SBA experiences reported points to the need for tailored education and emotional support provision to family members. Furthermore, the findings indicate that mental health professionals and civil servants need to acknowledge family members' familial relationships and responsibilities, in particular, the support they have provided to their family member with mental illness and their fears, concerns, and problems in that context. In-service training for mental health professionals and civil servants should therefore include opportunities for debate, discussion, and social skills development as they pertain to these needs.

We recommend that future research include longitudinal research that involves PWMI and their immediate family members and that explores the interactions between perceived SBA, self-stigma, and self-withdrawal. Further quantitative research on the possible relationship between the type of mental illness and SBA experiences is recommended as well. Additionally, future research should take familial relationship, co-residence, and gender into account.

\section{CONFLICTS OF INTEREST}

The authors declare no conflicts of interest. 


\section{REFERENCES}

Angermeyer, M. C., Schulze, B., \& Dietrich, S. (2003). Courtesy stigma: A focus group study of relatives of schizophrenia patients. Social Psychiatry Psychiatric Epidemiology, 38, 593-602. DOI: 10.1007/s00127-003-0680-x

Bazeley, P. (2007). Qualitative data analysis with NVivo. (pp. 6-15.). London: Sage Publications Ltd.

Bos, A. E. R., Kanner, D., Muris, P., Janssen, B., \& Mayer, B. (2009). Mental illness stigma and disclosure: Consequences of coming out of the closet. Issues in Mental Health Nursing, 30, 509-513. DOI: $10.1080 / 01612840802601382$

Bos, A. E. R., Pryor, J. B., Reeder, G. D., \& Stutterheim, S. E. (2013). Stigma: Advances in theory and research. Basic and Applied Social Psychology, 35(1), 1-9. DOI: 10.1080/01973533.2012.746147

Bos, A. E. R., Schaalma, H. P., \& Pryor, J. B. (2008). Reducing AIDS-related stigma in developing countries: The importance of theory- and evidence based interventions. Psychology, Health \& Medicine, 13, 450-460. DOI: 10.1080/13548500701687171

Burnard, P. (2004). A method of analysing interview transcripts in qualitative research. Nurse Education Today, 11(6), 461-466. DOI: 10.1016/0260-6917(91)90009-Y

Burnard, P., Gill, P., Stewart, E., Treasure, K., \& Chadwick, B. (2008). Analysing and presenting qualitative data. British Dental Journal, 204, 429-432. DOI: 10.1038/sj.bdj.2008.292

Conde-Sala, J. L., Garre-Olmo J., Turro-Garriga O., Vilalta-Franch J., \& Lopez-Pousa S. (2010). Differential features of burden between spouse and adult-child caregivers of patients with Alzheimer's disease: An exploratory comparative design. International Journal of Nursing Studies, 47(10), 1262-1273. DOI: 10.1016/j.ijnurstu.2010.03.001

Corrigan, P. W., \& Miller, F. E. (2004). Shame, blame, and contamination: A review of the impact of mental illness stigma on family members. Journal of Mental Health, 13(6), 537-548. DOI: 10.1080/09638230400017004

Corrigan, P. W., Watson, A. C., \& Miller, F. E. (2006). Shame, blame, and contamination: The impact of mental illness and drug dependence stigma on family members. Journal of Family Psychology, 20, 239-246. DOI: 10.1037/0893-3200.20.2.239

Crocker, J., Major, B., \& Steele, C. (1998). Social stigma. In D. Gilbert, S. T. Fiske, \& G. Lindzey (Eds.), The handbook of social psychology (pp. 504-553.). New York: McGraw Hill.

Dovidio, J. F., Major, B., \& Crocker, J. (2000). Stigma: Introduction and overview. In T. F. Heatherton, R. E. Kleck, M. R. Hebl \& J. G. Hull (Eds.), The social psychology of stigma (pp. 1-29.). New York: Guilford Press.

Eagly, A. H., Wood, W., \& Diekman, A. (2000). Social role theory of sex differences and similarities: A current appraisal. In T. Eckes \& H. M. Trautner (Eds.), The developmental social psychology of gender (pp. 123-174.). Mahwah, NJ: Lawrence Erlbaum.

Eldering, L. (2006). Cultuur en opvoeding. Rotterdam, The Netherlands: Uitgeverij Lemniscaat.

Farina, A. (1981). Are women nicer people than men? Sex and the stigma of mental disorders. Clinical Psychology Review, 1, 223-243. DOI: 10.1016/0272-7358 (81) 90005-2

Farina, A. (2000). The few gains and many losses for those stigmatized by psychiatric disorders. In J. H. Harvey \& E. D. Miller (Eds.), Loss and trauma: General and close relationship perspectives (pp. 183-207.). Philadelphia, PA: Brunner-Routledge.

Goffman, E. (1963). Stigma: Notes on the management of spoiled identity. Englewood Cliffs, NJ: Prentice-Hall.

Kulik, C. T., Bainbridge, H. T., \& Cregan, C. (2008). Known by the company we keep: Stigmaby-association effects in the workplace. Academy of Management Review, 33(1), 216-230. DOI: 10.5465/AMR.2008.27752765

Lanquetot, R. (1988). First person account: On being daughter and mother. Schizophrenia Bulletin, 14, 337-341. DOI: 10.1093/schbul/14.2.337

Larson, E. J., \& Corrigan, P. W. (2008). The stigma of families with mental illness. Academic Psychiatry, 32(2), 87-91. DOI: 10.1176/appi.ap.32.2.87

Lefley, H. (1989). Family burden and family stigma in major mental illness. American Psychologist, 44(3), 556-560. DOI: 10.1037/0003-066X.44.3.556

Lincoln, Y. S., \& Guba, E. G. (1985). Naturalistic inquiry. Newbury Park, CA: Sage Publications. 
Link, B. G., \& Cullen, F. T. (1990). The labeling theory of mental disorder: A review of the evidence. In J. Greenley (Ed.), Mental illness in social context (pp. 75-106). Greenwich, CT: JAI Press.

Link, B. G., Cullen, F. T., Struening, E. L., Shrout, P. E., \& Dohrenwend, B. P. (1989). A modified labelling theory approach to mental disorders: An empirical assessment. American Sociological Review, 54, 400-423. DOI: 10.2307/2095613

Mehta, S. I., \& Farina, A. (1988). Associative stigma: Perceptions of the difficulties of college-aged children of stigmatized fathers. Journal of Social and Clinical Psychology, 7(2). 192-202. DOI: $10.1521 /$ jscp.1988.7.2-3.192

Östman, M., \& Kjellin, L. (2002). Stigma by association, psychological factors in family members of people with mental illness. British Journal of Psychiatry, 181, 494-498. DOI: 10.1192/ bjp.181.6.494

Phelan, J. C., Bromet, E. J., \& Link, B. G. (1998). Psychiatric illness and family stigma. Schizophrenia Bulletin, 24, 115-126. DOI: 10.1093/oxfordjournals.schbul.a033304

Philips, R., \& Benoit, C. (2013). Exploring stigma by association among front-line care providers serving sex workers. Healthcare Policy, 9, 131-151. DOI: 10.12927/hcpol.2013.23597

Polit, D. F., \& Beck, C. T. (2010). Essentials of nursing research. Philadelphia, PA: Wolters Kluwer Lippincott Williams \& Wilkins.

Pryor, J. B., Reeder, G. D., \& Monroe, A. E. (2012). The infection of bad company: Stigma by association. Journal of Personality and Social Psychology, 102(2), 224-241. DOI: 10.1037/a0026270

Stutterheim, S. E., Bos, A. E. R., Shiripinda, I., De Bruin, M., Pryor, J. B., \& Schaalma, H. P. (2011). HIV-related stigma in African and Afro-Caribbean communities in the Netherlands: Experiences, consequences and coping. Psychology \& Health, 27(4), 395-411. DOI: 10.1080/ 08870446.2011 .585426

Thomas, D. R. (2006). A general inductive approach for qualitative data analysis. American Journal of Evaluation, 27(2), 237-246. DOI: 10.1177/1098214005283748

Van der Sanden, R. L. M. (2006). Stigmatizing reactions of ward staff members in the Dutch sheltered workshops on people with a serious mental illness (Master's thesis). Retrieved from http:// www.stigma-research.com/page8.php

Van der Sanden, R. L. M., Bos, A. E. R., Stutterheim, S. E., Pryor, J. B., \& Kok, G. (2013). Experiences of stigma by association among family members of people with mental illness. Rehabilitation Psychology, 58(1), 73-80. DOI: 10.1037/a0031752

Van der Sanden, R. L. M., Stutterheim, S. E., Pryor, J. B., Kok, G.,\& Bos, A. E. R. (2014). Coping with stigma by association and family burden among family members of people with mental illness. Journal of Nervous and Mental Disease, 202(10), 1-9. DOI: 10.1097/NMD.0000000000000189

Veit, C. T., \& Ware, J. E. (1983). The structure of psychological distress and well-being in general populations. Journal of Consulting and Clinical Psychology, 51, 730-742. DOI: 10.1037/0022006X.51.5.730

Verhaeghe, M., \& Bracke P. (2012). Associative stigma among mental health professionals: Implications for professional and service user well-being. Journal of Health and Social Behavior, 53(1), 17-32. DOI: 10.1177/0022146512439453.

Weiner, B. (1995). Judgements of responsibility: A foundation for a theory of social conduct. New York, NY: Guilford Press.

Weiner, B., Perry, R. P., \& Magnusson, J. (1988). An attributional analysis of reactions to stigmas. Journal of Personality and Social Psychology, 55, 738-748. DOI: 10.1037//0022-3514.55.5.738

Wirth, J. H., \& Bodenhausen, G. V. (2009). The role of gender in mental-illness stigma: A national experiment. Psychological Science, 20(2), 169-173. DOI: 10.1111/j.1467-9280.2009.02282.x

\section{APPENDIX A: OVERVIEW ON FAMILIAL RELATIONSHIP, CO-RESIDENCE, AND GENDER PER PARTICIPANT}

\begin{tabular}{lccccc}
\hline Participant ID & Name & Age (years) & Familial relationship & Co-residence & Gender \\
\hline 1 & Renske & $56-60$ & Mother/sister & No & Female \\
\hline
\end{tabular}

(Continues) 
Appendix A. (Continued)

\begin{tabular}{llcccc}
\hline Participant ID & Name & Age (years) & Familial relationship & Co-residence & Gender \\
\hline 2 & Suzanne & $56-60$ & Mother & No & Female \\
3 & Emma & $56-60$ & Mother & No & Female \\
4 & Natasja & $56-60$ & Mother/spouse & Yes & Female \\
5 & Anja & $61-65$ & Mother/spouse & No & Female \\
6 & Karen & $56-60$ & Mother/daughter & No & Female \\
7 & Hans & $56-60$ & Father/spouse & No & Male \\
8 & Bas & $46-50$ & Father & Yes & Male \\
9 & Roy & $41-45$ & Spouse & Yes & Male \\
10 & Inge & $51-55$ & Spouse & No & Female \\
11 & Dick & $51-55$ & Spouse & Yes & Male \\
12 & Wendy & $56-60$ & Sister & No & Female \\
13 & Celia & $46-50$ & Sister & No & Female \\
14 & Liza & $26-30$ & Sister & No & Female \\
15 & Ria & $41-45$ & Sister & No & Female \\
16 & Wil & $61-65$ & Brother & No & Male \\
17 & Joep & $41-45$ & Brother & No & Male \\
18 & Theo & $26-30$ & Brother & No & Male \\
19 & Piet & $21-25$ & Brother/son & No & Male \\
20 & Erik & $36-40$ & Son & No & Male \\
21 & Max & $36-40$ & Son & Yes & Male \\
22 & Joey & $26-30$ & Son & No & Male \\
23 & Chris & $56-60$ & Son & Yes & Male \\
\hline
\end{tabular}

\$Categorised.

\section{APPENDIX B: CATEGORISED THEMES AND ITEMS}

\begin{tabular}{ll}
\hline Themes & \multicolumn{1}{c}{ Items } \\
\hline Public stigma & Being taken serious/incompetent \\
Stigma by association & Avoidance \\
Psychological distress & Dangerous \\
Perceived closeness & Negative treatment \\
Family support & Social exclusion \\
Suicide & Find him or her strange \\
Familial relationship & Self-imposed withdrawal \\
Family role & Shame \\
Gender & Guilt \\
Housing & Concealment advice \\
& Overprotective \\
& Pity \\
& Unpredictable/untrustworthy \\
& Contagiousness/heredity \\
& Appreciated/wanted/loved \\
& Nervous/tense \\
& Anxious/worried \\
& Depressed/sad/downhearted \\
& Moody/brooded \\
& Emotionally unstable \\
& \\
& \\
& \\
&
\end{tabular}


Appendix B. (Continued)

\begin{tabular}{ll}
\hline Themes & \multicolumn{1}{c}{ Items } \\
\hline & Financial hardship \\
Loneliness & Exhausting \\
Stress/irritation \\
Time consuming \\
Justice/prosecution/criminal activities \\
Quarrel/tussle \\
Missed career opportunities \\
Less close and caring family \\
Contact \\
Domestic support \\
Financial support \\
Familial relationship and family role \\
Caregiver respite \\
Gender differences \\
Impact living together \\
Being yourself \\
Having your own friends and company \\
Rooms/studying \\
\hline
\end{tabular}

APPENDIX C: CATEGORISED ITEMS REPORTED PER PARTICIPANT

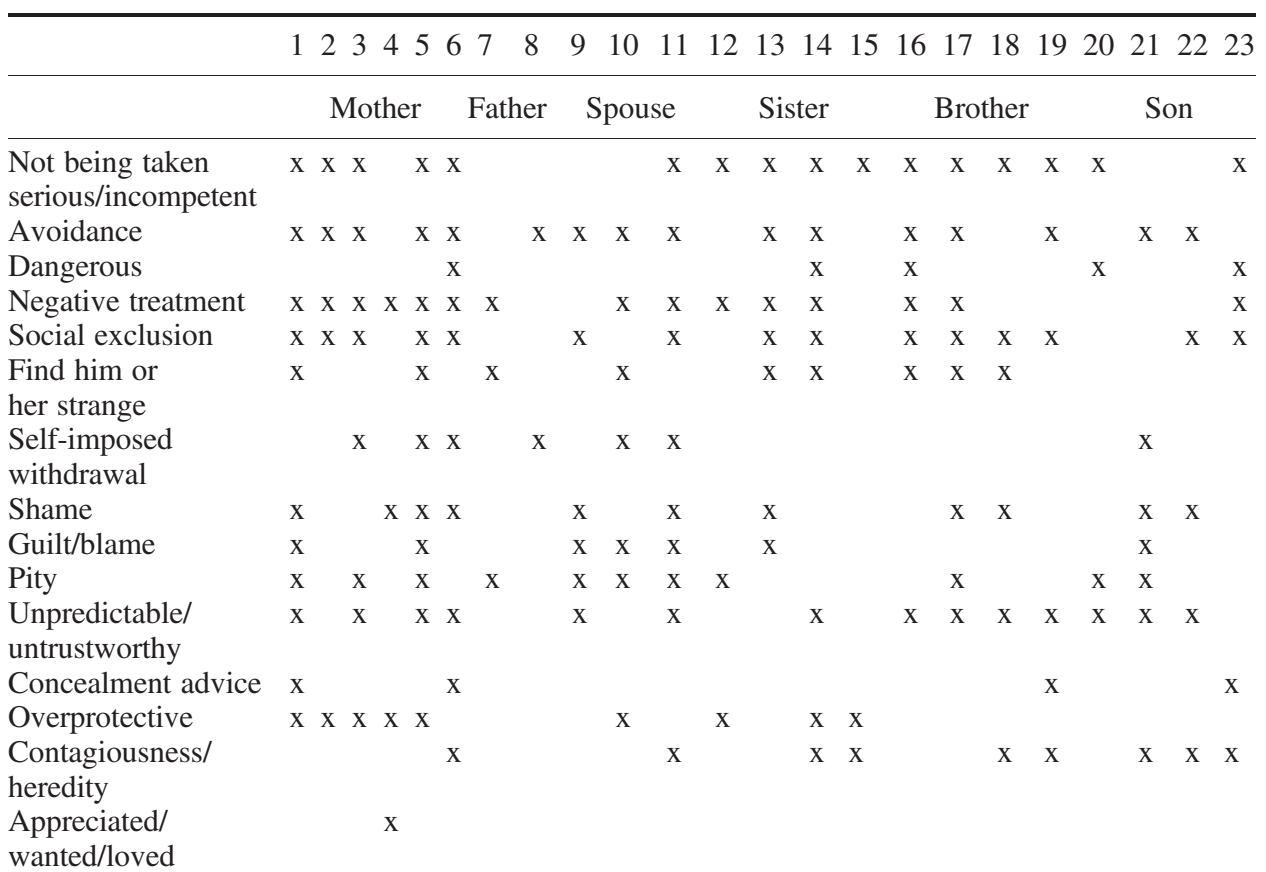


Appendix C. (Continued)

\begin{tabular}{|c|c|c|c|c|c|c|c|c|c|c|c|c|c|c|c|c|c|c|c|c|c|c|c|}
\hline & 1 & 2 & Mo & 4 & $\mathrm{r}$ & 6 & $\begin{array}{l}7 \\
\text { Fath }\end{array}$ & er & $\begin{array}{l}9 \\
\mathrm{~S}\end{array}$ & 10 & 11 & 12 & 13 & ter & 15 & 16 & 17 & 18 & 19 & 20 & 21 & 22 & \\
\hline Nervous/Tense & & & $\mathrm{X}$ & & & & & & $\mathrm{x}$ & & & & & & & $\mathrm{x}$ & & & & & & & \\
\hline Anxious/worried & $\mathrm{X}$ & $\mathrm{X}$ & & $\mathrm{x}$ & & & & & $\mathrm{x}$ & & & & & & & & & & & & & & \\
\hline $\begin{array}{l}\text { Depressed/ } \\
\text { downhearted/sad }\end{array}$ & $\mathrm{x}$ & $\mathrm{x}$ & & & & $\mathrm{x}$ & & & & & & & & & $\mathrm{x}$ & & & & & & & & $\mathrm{x}$ \\
\hline Moody/brooded & & $\mathrm{X}$ & $x$ & $\mathrm{x}$ & & & & & $\mathrm{x}$ & $\mathrm{X}$ & $\mathrm{X}$ & & $\mathrm{x}$ & & & & & & & & & & \\
\hline Emotionally unstable & & $\mathrm{x}$ & $x$ & & $\mathrm{x}$ & $\mathrm{x}$ & & & & $\mathrm{x}$ & & & $\mathrm{x}$ & & $\mathrm{x}$ & & & & & & & & \\
\hline Financial hardship & & & $\mathrm{X}$ & & & & $\mathrm{x}$ & & & $\mathrm{x}$ & $\mathrm{X}$ & & & & & $\mathrm{x}$ & & & $\mathrm{x}$ & & & $\mathrm{x}$ & \\
\hline Loneliness & $\mathrm{x}$ & & & $\mathrm{x}$ & $\mathrm{x}$ & & & & $\mathrm{X}$ & & & & & & & $\mathrm{x}$ & & & $\mathrm{x}$ & $\mathrm{X}$ & & & \\
\hline Exhausting & $\mathrm{x}$ & $\mathrm{x}$ & & $\mathrm{x}$ & $\mathrm{x}$ & & & & $\mathrm{x}$ & & $\mathrm{x}$ & $\mathrm{x}$ & & $\mathrm{x}$ & & & & $\mathrm{x}$ & & & & & $\mathrm{x}$ \\
\hline Stress/irritation & $\mathrm{X}$ & $\mathrm{X}$ & $x$ & $\mathrm{x}$ & $\mathrm{x}$ & & $\mathrm{x}$ & & $\mathrm{x}$ & & $\mathrm{x}$ & $\mathrm{x}$ & $\mathrm{X}$ & $\mathrm{x}$ & $\mathrm{x}$ & $\mathrm{X}$ & $\mathrm{x}$ & $\mathrm{x}$ & & & $\mathrm{x}$ & $\mathrm{x}$ & $\mathrm{x}$ \\
\hline Time consuming & & & $\mathrm{x}$ & $\mathrm{x}$ & $\mathrm{x}$ & & $\mathrm{x}$ & & $\mathrm{x}$ & & & $\mathrm{x}$ & & $\mathrm{x}$ & $\mathrm{x}$ & & & $\mathrm{x}$ & & & & & \\
\hline $\begin{array}{l}\text { Justice/prosecution/ } \\
\text { criminal activities }\end{array}$ & $\mathrm{x}$ & & & $\mathrm{x}$ & & & $\mathrm{x}$ & & & & $\mathrm{x}$ & & & $\mathrm{x}$ & & $\mathrm{x}$ & & & & & & $\mathrm{x}$ & \\
\hline Quarrel/tussle & $\mathrm{x}$ & & $\mathrm{x}$ & $\mathrm{x}$ & $\mathrm{x}$ & & $\mathrm{X}$ & $\mathrm{x}$ & $\mathrm{x}$ & & $\mathrm{x}$ & & & $\mathrm{x}$ & & $\mathrm{x}$ & $\mathrm{x}$ & $\mathrm{x}$ & & & $\mathrm{X}$ & $\mathrm{x}$ & \\
\hline $\begin{array}{l}\text { Missed career } \\
\text { opportunities }\end{array}$ & & & $\mathrm{x}$ & & $\mathrm{x}$ & & & & & & & & & & $\mathrm{x}$ & & & $\mathrm{x}$ & & & & & \\
\hline $\begin{array}{l}\text { Less close and } \\
\text { caring family }\end{array}$ & $\mathrm{x}$ & $\mathrm{X}$ & & & $\mathrm{x}$ & $\mathrm{x}$ & $\mathrm{x}$ & & $\mathrm{x}$ & $\mathrm{X}$ & $\mathrm{x}$ & & & $\mathrm{x}$ & $\mathrm{x}$ & $\mathrm{x}$ & $\mathrm{x}$ & $\mathrm{x}$ & $\mathrm{x}$ & & $\mathrm{X}$ & $\mathrm{x}$ & \\
\hline Contact & $\mathrm{x}$ & & $\mathrm{X}$ & & & & & $\mathrm{x}$ & & & & $\mathrm{x}$ & & $\mathrm{x}$ & $\mathrm{x}$ & & $\mathrm{x}$ & $\mathrm{x}$ & $\mathrm{x}$ & $\mathrm{x}$ & & $\mathrm{x}$ & $\mathrm{x}$ \\
\hline Domestic support & & $\mathrm{x}$ & & $\mathrm{x}$ & & & & & $\mathrm{x}$ & $\mathrm{x}$ & $\mathrm{x}$ & $\mathrm{x}$ & & & & & $\mathrm{x}$ & & & & & $\mathrm{x}$ & \\
\hline Financial support & $\mathrm{x}$ & $\mathrm{x}$ & $x$ & & & $\mathrm{x}$ & $\mathrm{x}$ & & $\mathrm{x}$ & $\mathrm{X}$ & & & & & & $\mathrm{x}$ & & & $\mathrm{x}$ & & & & $\mathrm{x}$ \\
\hline $\begin{array}{l}\text { Familial relationship } \\
\text { and family role }\end{array}$ & & $\mathrm{x}$ & & $\mathrm{x}$ & & & $\mathrm{x}$ & & & & $\mathrm{x}$ & & $\mathrm{x}$ & $\mathrm{x}$ & $\mathrm{x}$ & & $\mathrm{x}$ & $\mathrm{x}$ & $\mathrm{x}$ & & & $\mathrm{x}$ & \\
\hline Caregiver respite & $\mathrm{x}$ & $\mathrm{x}$ & $\mathrm{x}$ & $\mathrm{X}$ & $\mathrm{x}$ & & & & $\mathrm{x}$ & $\mathrm{X}$ & & & & & $\mathrm{x}$ & & & & & & & & \\
\hline Gender differences & $\mathrm{x}$ & $\mathrm{x}$ & $x$ & $\mathrm{x}$ & & & $\mathrm{x}$ & & & & & & & $\mathrm{x}$ & & & & & & & & & \\
\hline $\begin{array}{l}\text { Impact living } \\
\text { together }\end{array}$ & & & & $\mathrm{X}$ & $\mathrm{x}$ & & & & & & $\mathrm{x}$ & & $\mathrm{x}$ & $\mathrm{x}$ & $\mathrm{x}$ & $\mathrm{x}$ & $\mathrm{x}$ & & $\mathrm{x}$ & $\mathrm{x}$ & $\mathrm{x}$ & & \\
\hline Being yourself & $\mathrm{x}$ & & & $\mathrm{X}$ & & & $\mathrm{x}$ & & $\mathrm{X}$ & & $\mathrm{x}$ & $\mathrm{X}$ & $\mathrm{X}$ & $\mathrm{x}$ & $\mathrm{x}$ & $\mathrm{x}$ & $\mathrm{x}$ & $\mathrm{x}$ & $\mathrm{x}$ & & $\mathrm{x}$ & $\mathrm{x}$ & \\
\hline $\begin{array}{l}\text { Having your } \\
\text { own friends } \\
\text { and company }\end{array}$ & & & & $\mathrm{x}$ & & & & & & & $\mathrm{x}$ & & $\mathrm{x}$ & $\mathrm{x}$ & $\mathrm{x}$ & $\mathrm{x}$ & $\mathrm{x}$ & $\mathrm{x}$ & $\mathrm{x}$ & & $\mathrm{x}$ & $\mathrm{x}$ & \\
\hline Rooms/studying & & & & & & & & & & & & & & $\mathrm{x}$ & $\mathrm{x}$ & & $\mathrm{x}$ & $\mathrm{x}$ & $\mathrm{x}$ & & & $\mathrm{x}$ & \\
\hline
\end{tabular}

